(2) Open Access Full Text Article

\title{
Lacrimal drainage anomalies in congenital rubella syndrome
}

This article was published in the following Dove Press journal:

Clinical Ophthalmology

9 November 2017

Number of times this article has been viewed

\author{
Shweta Gupta \\ Mohammad Javed Ali \\ Milind N Naik \\ Govindram Seksaria Institute of \\ Dacryology, L.V. Prasad Eye Institute, \\ Hyderabad, India
}

Purpose: The objective of this study was to ascertain the lacrimal drainage anomalies in a cohort of patients suffering from congenital rubella syndrome (CRS).

Methods: This was a retrospective case series performed in patients with CRS presenting with associated lacrimal drainage anomalies (LDA) over 6 years from 2011 to 2016 . All the patients were confirmed as having CRS after clinical and laboratory testing. Data collected include demographics; associated lacrimal, ocular, and systemic anomalies; interventions performed for lacrimal anomalies; and their anatomical and functional outcomes.

Results: Eighty five patients were diagnosed as having CRS during the study period, and of these 23 eyes of 12 patients with associated LDA were included in the study. The prevalence of LDA was $14 \%$ in CRS. The mean age at presentation was 15.5 weeks, and all except one had bilateral presentation. Seventeen eyes were diagnosed with simple congenital nasolacrimal duct obstruction (CNLDO) and the remaining six eyes had complex CNLDO with buried probes. Additional lacrimal anomalies noted in the six complex CNLDO cases included punctal agenesis $(n=3)$, atonic sac $(n=3)$, incomplete punctal canalization $(n=2)$, and single canalicular wall hypoplasia $(\mathrm{n}=1)$. At a mean follow-up of 12.54 months, anatomical and functional success were noted in $91.3 \%$ (21/23 eyes).

Conclusion: Simple CNLDO was the most common of the LDA in CRS. Buried probe was universal among the cases with complex CNLDO. All CRS patients should be screened for lacrimal anomalies to initiate appropriate interventions for successful outcomes.

Keywords: rubella, lacrimal drainage, CNLDO, buried probe, punctal agenesis

\section{Introduction}

Congenital rubella syndrome (CRS) is a term applied to the consequences of an in utero transplacental rubella virus infection. It consists of the classical triad of ocular defects, sensorineural hearing loss, and cardiac anomalies. ${ }^{1-3}$ The fetus is susceptible to the widespread systemic effects of the virus because of organogenesis and lack of immunity. Ocular abnormalities are common and include congenital cataract, congenital glaucoma, pigmentary retinopathy, microphthalmia, and many others. ${ }^{3-14}$ Lacrimal drainage anomalies have sparsely been documented with CRS, and in the form of a nonspecific dacryostenosis, there is reported prevalence of $2 \%-4 \%$ in various studies. ${ }^{4,6}$ The current study presents the various forms of lacrimal drainage anomalies (LDA) associated with CRS, their clinical profile, management, and outcomes.

\section{Methods}

A retrospective chart review of all CRS patients who presented with associated LDA over 6 years from 2011 to 2016 was performed. The institutional review board and ethics committee of L.V. Prasad Eye Institute approved this study. Written informed 
consent was obtained from the parents or legal guardians. All the patients were clinically and laboratory confirmed as having CRS and were referred from pediatric institutions for management of ocular abnormalities. Clinical confirmation was based on the World Health Organization surveillance standards, and laboratory confirmation was a positive blood test for rubellaspecific IgM antibodies. Data collected include demographics; associated lacrimal, ocular, and systemic anomalies; interventions performed for lacrimal anomalies; and their anatomical and functional outcomes. LDA from the punctum to the nasolacrimal opening in the inferior meatus were assessed. Irrigation and probing were performed under endoscopic guidance. A simple congenital nasolacrimal duct obstruction (CNLDO) was defined as a membranous obstruction at the inferior-most end of the nasolacrimal duct that could be easily overcome without much resistance. ${ }^{15} \mathrm{CNLDO}$ associated with other lacrimal anomalies or craniofacial or developmental nasolacrimal duct (NLD) defects were grouped as complex. ${ }^{15}$ Antibiotic prophylaxis was administered for infants with associated cardiac anomalies before probing. In addition to irrigation and probing, probe exteriorization was performed for buried probes as per standard protocols published, ${ }^{16}$ and intubation was performed in two of these cases following thick buried probe exteriorization. Membranotomy, as described earlier, ${ }^{17}$ was performed for cases of incomplete punctal canalization. Anatomical success was defined as patency of lacrimal drainage system following probing, and functional success as resolution of epiphora.

\section{Results}

A total of 85 patients were diagnosed as having CRS during the study period, and of these 23 eyes of 12 patients with associated LDA were included in the study. All these 12 patients had cardiac anomalies, while sensorineural hearing loss was noted in 4 patients and microcephaly and micrognathia were noted in 2 patients. The prevalence of LDA was 14\% among CRS patients in this series. The mean age at presentation was 15.25 weeks (range: 3-48 weeks). Epiphora was the universal complaint, and all except one had a bilateral presentation. $75 \%(9 / 12)$ additionally presented with discharge. None of the patients had any lacrimal intervention in the past. Of the 23 eyes, ocular abnormalities noted include congenital cataract $(n=16)$, salt and pepper retinopathy $(n=5)$, congenital glaucoma $(n=2)$, nystagmus $(n=5)$, and microcornea $(n=5)$. Of the 23 eyes, 17 were diagnosed with simple CNLDO, and the remaining 6 eyes had complex CNLDO with buried probes. Additional lacrimal anomalies noted in the six complex CNLDO cases include punctal agenesis $(n=3$; upper punctum $=2$, lower punctum $=1$, atonic sac $(n=3)$, incomplete
Table I LDA associated with CRS

\begin{tabular}{ll}
\hline Lacrimal drainage system anomalies & Number of eyes (n) \\
\hline Simple CNLDO & 17 \\
Complex CNLDO & 6 \\
Punctal agenesis & 3 (UP-2, LP-I) \\
Atonic sac & 3 \\
Incomplete punctal canalization & 2 (I UP, I-LP) \\
Single canalicular wall hypoplasia & I (upper canaliculus) \\
\hline
\end{tabular}

Abbreviations: LDA, lacrimal drainage anomalies; CRS, congenital Rubella syndrome; CNLDO, congenital nasolacrimal duct obstruction; UP, upper punctum; LP, lower punctum.

punctal canalization $(\mathrm{n}=2)$, and single canalicular wall hypoplasia $(n=1)$ (Table 1). All patients underwent irrigation and probing under endoscopic guidance and with antibiotic prophylaxis for infective endocarditis. Two patients with complex CNLDO had thick buried probes and underwent probe exteriorization and intubation. Two cases of incomplete punctal canalization underwent a successful membranotomy followed by probing. At a mean follow-up of 12.54 months (range: 2-45 months), anatomical and functional success were noted in $91.3 \%$ (21/23 eyes). Two eyes with complex CNLDO and buried probes failed the probing and intubation and are awaiting a dacryocystorhinostomy.

\section{Discussion}

This study focused on the analysis of LDA in patients with clinical- and laboratory-proven CRS. Although simple CNLDO was the most common anomaly, buried probe was universal among the complex CNLDO cases. Intervention led to high success rates; however, some complex CNLDO's remained recalcitrant to irrigation, probing, and intubation and would eventually require a dacryocystorhinostomy.

Lacrimal drainage system starts developing at roughly around 10 weeks of intrauterine life and continues to develop till around the 7 th month. Since early or first-trimester infection are associated with robust organogenesis defects, it is possible that the early in utero infections may lead to the kind of abnormalities as seen in this series, eg, punctal agenesis and single canalicular wall hypoplasia. Subsequent late infections may explain the predisposition to various types of CNLDO.

Vijayalakshmi et $\mathrm{al}^{12}$ studied 87 eyes of 46 infants and found the prevalence of congenital dacryostenosis to be $2.3 \%(2 / 87)$. Givens et $\mathrm{al}^{6}$ studied 125 cases of CRS over a 32 year interval and found $2 \%(3 / 125)$ of them to present with unilateral dacryostenosis. Similarly, Geltzer et $\mathrm{al}^{4}$ studied 48 eyes with CRS during the 1964-1965 rubella epidemic in United States and found that the prevalence of lacrimal duct obstruction was $4 \%(2 / 48)$, and all of these cases responded 
well with probing. Roy et $\mathrm{al}^{5}$ quoted Lundstrom's report mentioning significant association of CRS with dacryostenosis, but no further details could be found. It is important to note that none of these studies defined what they meant by dacryostenosis, and most had no information with regard to their management strategies and patient outcomes. The prevalence of lacrimal anomalies in CRS in the current study is much higher (14\%) than that reported in the literature, and multiple new lacrimal anomalies are also described. This can be attributed to the wider awareness at a tertiary-care institute and focused efforts to evaluate lacrimal drainage system in all patients with CRS.

Since patients with CRS have cardiac anomalies, all patients in this study were prescribed prophylactic antibiotics before probing to prevent the risk of infective endocarditis. Since probing-induced bacteremia has been demonstrated in cases of acute dacryocystitis but not the routine cases of CNLDO in systemically healthy infants, ${ }^{18}$ it is recommended to give prophylaxis to patients at risk of developing infective endocarditis. ${ }^{19,20}$

\section{Conclusion}

In conclusion, the current study is the first of its kind to provide a comprehensive assessment of LDA in CRS. The study provides useful insights into the wide range of associated LDA and the outcomes of interventions in such cases. There is a need to include lacrimal drainage assessment in all CRS patients while screening for ocular abnormalities.

\section{Disclosure}

Mohammad Javed Ali received support from the Alexander von Humboldt Foundation for his research and he also receives royalties from Springer for the textbook "Principles and Practice of Lacrimal Surgery." The authors report no other conflicts of interest in this work.

\section{References}

1. Felicity TC, Jennifer B, Merilda MS, Kristina E, Susan ER. Guidelines for surveillance of congenital rubella syndrome and rubella. Field test version. Bull World Health Organ. 1999;22:12.
2. South MA, Sever JL. Teratogen update: the congenital rubella syndrome. Teratology. 1985;31:297-307.

3. Saraswathy TS, Rozainanee MZ, Asshikin RN, et al. Congenital rubella syndrome: a review of laboratory data from 2002 to 2011. Southeast Asian J Trop Med Public Health. 2013;44:429-435.

4. Geltzer AL. Ocular manifestations of the 1964-1965 rubella epidemic. Am J Ophthalmol. 1967;63:221-229.

5. Roy FH, Hiatt RL, Korones SB, Roane J. Ocular manifestations of congenital rubella syndrome. Recovery of virus from affected infants. Arch Ophthalmol. 1966;75:601-607.

6. Givens KT, Lee DA, Jones T, Ilstrup DM. Congenital rubella syndrome: ophthalmic manifestations and associated systemic disorders. $\mathrm{Br} J$ Ophthalmol. 1993;77:358-363.

7. Arnold JJ, McIntosh ED, Martin FJ, Menser MA. A fifty-year follow-up of ocular defects in congenital rubella: late ocular manifestations. Aust N Z J Ophthalmol. 1994;22:1-6.

8. Arnold J. Ocular manifestations of congenital rubella. Curr Opin Ophthalmol. 1995;6:45-50.

9. Boniuk V. Systemic and ocular manifestations of the rubella syndrome. Int Ophthalmol Clin. 1972;12:67-76.

10. Armstrong NT. The ocular manifestations of congenital rubella syndrome. Insight. 1992;17:14-16.

11. Alfano JE. Ocular aspects of maternal rubella syndrome. Trans Am Acad Ophthal Otolaryng. 1996;70:235-266.

12. Vijayalakshmi P, Kakkar G, Samprathi A, et al. Ocular manifestations of congenital rubella syndrome in a developing country. Indian $J$ Ophthalmol. 2002;50:307-311.

13. Vijayalakshmi P, Rajasundari TA, Prasad NM, et al. Prevalence of eye signs in congenital rubella syndrome in South India: a role for population screening. Br J Ophthalmol. 2007;91:1467-1470.

14. Khandekar R, Al Awaidy S, Ganesh A, et al. An epidemiological and clinical study of ocular manifestations of congenital rubella syndrome in Omani children. Arch Ophthalmol. 2004;122:541-545.

15. Ali MJ, Kamal S, Gupta A, et al. Simple versus complex congenital nasolacrimal duct obstructions: etiology, management and outcomes. Int Forum Allergy Rhinol. 2015;5:174-177.

16. Gupta A, Kamal S, Javed Ali M, et al. Buried probe in complex congenital nasolacrimal duct obstructions: clinical profiles and outcomes. Ophthal Plast Reconstr Surg. 2015;31:318-320.

17. Ali MJ, Mohapatra S, Mulay K, et al. Incomplete punctal canalization: the external and internal punctal membranes. Outcomes of membranotomy and adjunctive procedures. Br J Ophthalmol. 2013;97:92-95.

18. Ganguly A, Ali MJ, Padmaja K, et al. Bacteremia following nasolacrimal duct probing: is there a role of pre-operative antibiotic prophylaxis? Ophthal Plast Reconstr Surg. 2016;32:90-92.

19. Eippert GA, Burnstine RA, Bates JH. Lacrimal duct probing induced bacteremia: should children with congenital heart defects receive antibiotic prophylaxis? J Pediatr Ophthalmol Strabismus. 1998;35:38-40.

20. Grech V, Sammut P, Parascandolo R. Bacterial endocarditis following lacrimal duct probing. J Pediatr Ophthalmol Strabismus. 2001;38: $49-50$
Clinical Ophthalmology

\section{Publish your work in this journal}

Clinical Ophthalmology is an international, peer-reviewed journal covering all subspecialties within ophthalmology. Key topics include: Optometry; Visual science; Pharmacology and drug therapy in eye diseases; Basic Sciences; Primary and Secondary eye care; Patient Safety and Quality of Care Improvements. This journal is indexed on Submit your manuscript here: http://www.dovepress.com/clinical-ophthalmology-journal

\section{Dovepress}

PubMed Central and CAS, and is the official journal of The Society of Clinical Ophthalmology (SCO). The manuscript management system is completely online and includes a very quick and fair peer-review system, which is all easy to use. Visit http://www.dovepress.com/ testimonials.php to read real quotes from published authors. 